\title{
The Use of L-arginine Supplements for Cardiovascular Disease and Related Disorders is Questionable
}

John L Ivy*

Department of Kinesiology and Health Education, USA

ISSN: 2640-9208

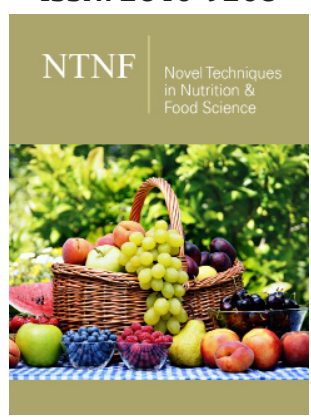

*Corresponding author: John L Ivy, Department of Kinesiology and Health Education, USA

Submission: 1 眥 August 19, 2020

Published: 海 September 10, 2020

Volume 5 - Issue 1

How to cite this article: John L Ivy. The Use of L-arginine Supplements for Cardiovascular Disease and Related Disorders is Questionable. Nov Tech Nutri Food Sci. 5(1). NTNF. 000604. 2020. DOI: 10.31031 /NTNF.2020.05.000604

Copyright@ John L Ivy. This article is distributed under the terms of the Creative Commons Attribution 4.0 International License, which permits unrestricted use and redistribution provided that the original author and source are credited.

\begin{abstract}
Purpose: L-arginine supplementation has been tested as a treatment for various conditions related to cardiovascular disease, but with mixed results. This article reviews the research findings related to the effects of L-arginine supplementation on the cardiovascular system of individuals with cardiovascular disease and related disorders.

Design/methodology/approach: Research and review articles were identified through the search engines Google Scholar, PubMed and ScienceDirect. Main key words included L-arginine, supplementation, nitric oxide, cardiovascular disease, hypertension, endothelia dysfunction, atherosclerosis, and exercise capacity.

Findings: Supplementation of L-arginine for short periods of time has been found useful in treating cardiovascular diseases including hypertension, atherosclerosis, coronary heart disease, heart failure, peripheral vascular disease and type 2 diabetes, but efficacy requires very high daily dosages ranging from 6 to $24 \mathrm{~g}$ per day. However, prolonged supplementation with L-arginine generally has not been found to effectively treat cardiovascular related abnormalities, and under some conditions it has been found to be harmful.

Originality: This review provides insight into the efficacy of using L-arginine as a treatment for cardiovascular disease and related abnormalities. While short-term supplementation appears to provide some beneficial effects, its long-term use is highly questionable and could have adverse consequences. Therefore, careful consideration should be given before using L-arginine as a supplement to treat cardiovascular related diseases.
\end{abstract}

Keywords: L-arginine; Nitric oxide; Cardiovascular disease; Atherosclerosis; Endothelial dysfunction; Hypertension; Exercise

\section{Introduction}

L-Arginine is a proteinogenic, conditionally essential amino acid. It is involved in various metabolic pathways including the synthesis of creatine, L-ornithine, L-glutamate, and polyamines, and protein degradation by the ubiquitin-proteasome pathway [1]. One of its most important functions, however, is serving as substrate for the production of nitric oxide (NO) via the nitric oxide synthases (NOS) [2]. There are three isoforms of the NOS enzyme with nNOS or NOS-1, the isoform found in neuronal and muscle tissue, the first to be identified. The second isoform identified was iNOS or NOS-2. This isoform is inducible in a wide range of cells and tissues, most notably in immune cell. The third isoform identified was eNOS or NOS-3, which was found in vascular endothelial cells. Although there are some structural differences among these NOS enzymes, in their active form they are homodimeric and require the coenzymes NADPH, FAD, and FMN as well as heme iron, tetrahydrobiopterin, and oxygen [3].

The importance of NO cannot be overstated. However, research indicates that NOS activity declines by approximately $50 \%$ from ages 20 to 45 [4]. This decline has been associated with many metabolic disorders including, hypertension, cardiovascular disease, type 2 diabetes, kidney complications and sarcopenia to name but a few [5,6]. Because of its significant influence throughout the body, means of increasing NO production have been investigated including increasing the availability of its substrate, L-arginine. 
The research related to increasing NO secretion by L-arginine supplementation has primarily focused on improving cardiovascular health and skeletal muscle function and performance. Research suggests that infusion or short-term oral supplementation of L-arginine might be useful in the treatment of hypertension, endothelial dysfunction, coronary heart disease, heart failure, and peripheral vascular disease [7-10]. However, not all research studies have demonstrated positive effects of L-arginine supplementation. In fact, a number of studies, particularly long-term studies, have demonstrated no beneficial effect of L-arginine supplementation for patient populations with underlying cardiovascular abnormalities, and some studies have actually found that L-arginine supplementation can cause significant adverse events.

This article is a review of the research findings related to the effects of L-arginine supplementation on the cardiovascular system of individuals with cardiovascular disease and related disorders. While research findings suggest that high dosages of L-arginine supplementation for short periods of time might be beneficial, it appears that long-term supplementation is likely to be counterproductive and may have severe consequences.

\section{Methods}

Research and review articles were identified and ascertained from the search engines Google Scholar, PubMed and ScienceDirect. Keywords that were used in the search included L-arginine, supplementation, nitric oxide, cardiovascular disease, hypertension, endothelia dysfunction, atherosclerosis and exercise. With few exceptions, research articles reviewed were limited to human clinical trials or meta-analyses.

\section{Effective L-arginine Supplementation}

Positive effects of infusion or oral supplementation of L-arginine have been found in a number of clinical conditions including coronary artery disease, hypertension, heart failure, hypercholesterolemia, peripheral vascular disease and type 2 diabetes [7-11]. Even very high oral doses of L-arginine can result in vasodilation in young, healthy individuals [12], and improve flow-mediated endothelium-dependent vasodilation of healthy middle-aged and older populations [13].

\section{Endothelial function}

Numerous studies have been conducted to investigate the effects of L-arginine supplementation on endothelial function in individuals with various cardiovascular complications. For example, Adams and colleagues [7] investigated the effects of L-arginine in premature coronary artery disease patients. The patients, with an average age of 41 years, were provided $21 \mathrm{~g}$ of L-arginine per day for 3 days. After treatment it was found that flow-mediated vasodilation was significantly improved in the brachial artery, and monocyte adhesion improved. Likewise, Clarkson et al. [11] found that hypercholesterolemic patients who received $7 \mathrm{~g}$ of L-arginine three times per day for 4 weeks had improved endothelium-dependent forearm blood flow and dilation of the conduit arteries. In a longterm study, Lerman et al. [14] reported that after receiving 9g of L-arginine per day for 6 months, coronary artery disease patients showed substantial improvement in coronary artery response to acetylcholine infusion. Lerman et al. [14] substantiated this finding, but also observed that the improvement in coronary artery responsiveness was related to a decrease in plasma endothelin-1 levels, a strong vasoconstrictor.

\section{Platelet and monocyte regulation}

Damage to the end othelial lining of the arteries and arterioles is primarily responsible for abnormal vascular reactivity. Endothelial dysfunction originates with insufficient control over anticoagulant substances and vascular inflammation. With a decline in eNOS activity comes a decline in regulation of platelet function, increase in monocyte adhesion and migration, smooth muscle cell proliferation and advancement of atherosclerosis [15,16]. Positive outcomes related to control over platelets and monocytes have been noted following supplementation with L-arginine $[17,18]$. Wolf et al. [18] found that L-arginine supplementation normalized platelet aggregation in individuals who were hypercholesterolemic. Asymmetric dimethylarginine (ADMA), an endogenous inhibitor of nitric oxide synthase, is typically elevated in hypercholesterolemic patients. In this regard, Chan et al. [19] found that monocyte adhesiveness in this patient population was inversely correlated with the plasma L-arginine/ADMA ratio. Furthermore, oral administration of L-arginine for 12 weeks normalized the plasma L-arginine/ADMA ratio and lessened monocyte adhesiveness.

\section{Hypertension}

NO is of considerable importance to blood pressure regulation and limiting NO production due to a decline in eNOS activity has been linked to atypical blood pressure regulation. Numerous studies have demonstrated that blood pressures of hypertensive and pre-hypertensive individuals can be substantially reduced following elevations in NO by acute and chronic inorganic nitrate supplementation [20-23]. Likewise, L-arginine supplementation has been found to reduce blood pressure. L-arginine appears to be effective in lowering the blood pressure of patients with various metabolic disorders. For example, Facchinetti and colleagues [24] found that infusion of $20 \mathrm{~g} / 500 \mathrm{ml}$ daily for 5 day and then $4 \mathrm{~g}$ per day orally for 2 weeks significantly lowered both systolic and diastolic blood pressure of patients with gestational hypertension. Similarly, women with polycystic ovary syndrome and elevated blood pressure due to their oral contraceptive were found to respond well to L-arginine supplementation [25]. This was demonstrated with a normalization of blood pressure and improved endotheliumdependent vasodilation. L-arginine supplementation was also found to improve the blood pressure and insulin resistance of type 2 diabetics [26]. Patients were placed on a hypocaloric diet and then randomly divided into two groups. One group received a placebo for 2 months.

The second group received a placebo for the first month and then L-arginine ( $3 g$ three times per day) the second month. Systolic blood pressure remained unchanged in the placebo group, whereas in the L-arginine group it fell from $128 \pm 4$ to $110 \pm 3 \mathrm{mmHg}$, a $14 \%$ decline. Lucotti et al. [27] also found a substantial improvement in the blood pressure of type 2 diabetics when provided L-arginine 
supplements (8.3g per day) during 21 days of a weight management program. In addition, four weeks of L-arginine supplementation was found to improve the arginine/ADMA ratio and lower the blood pressure of hypertensive patients with micro-vascular angina [10], and the blood pressure of primary mild hypertensive patients [28]. Finally, from the cumulative results of a meta-analysis, it was concluded that L-arginine supplementation lowers systolic and diastolic blood pressure by approximately $5 \mathrm{mmHg}$ and $2 \mathrm{mmHg}$, respectively. However, it should be noted that the majority of the studies evaluated did not find blood pressure significantly lowered by L-arginine supplementation, although it was reduced to some degree in most of the studies [29].

\section{Cardiovascular disease and exercise capacity}

Raising NO levels by pharmacological or nutrient supplementation has been found to have a profound positive effect on exercise capacity in healthy individuals and those with cardiovascular disease. Therefore, it is not surprising that elevating endogenous NO production with L-arginine supplementation has been found to improve exercise capacity in coronary disease patients, and those with healed myocardial infarction [30,31]. Moreover, oral L-arginine supplementation $(8 \mathrm{~g} / \mathrm{d})$ was found to improve endothelium-dependent vasodilation in patients with heart failure, and this beneficial effect was additive with exercise training [32]. In addition, L-arginine supplementation has been found to produce greater pain-free exercise and total walking distance in peripheral vascular disease patients [33] and improve forearm blood flow, walking distance, and subjective symptoms in patients with chronic heart failure [34]. More recently, Doutreleau et al. [31] reported that chronic supplementation of L-arginine (6g/d twice a day for 6 weeks) delayed the ventilator threshold and reduced blood lactate levels during exercise of heart failure patients suggesting supplementation could result in a great aerobic work capacity.

\section{Ineffective L-arginine Supplementation}

As presented, there are a number of research studies that suggest L-arginine supplementation could be of benefit to individuals with cardiovascular disease or heart failure. However, not all research studies support these findings. In fact, there are numerous research studies that have found no benefit of L-arginine supplementation as it relates to cardiovascular disease, myocardial function or exercise capacity. More importantly, several of these studies indicated that the long-term supplementation of L-arginine could have significant harmful effects.

\section{Endothelial function}

Schulman et al. [35] started evaluation of 153 patients with stable coronary artery disease at 3 to 21 days after their first myocardial infarction. Patients were randomly assigned to receive $3 \mathrm{~g}$ of L-arginine 3 times per day for 6 months or a placebo. Vascular function was not improved by L-arginine supplementation. Arterial compliance, pulse pressure, and pulse wave velocity were similar between placebo and L-arginine treated patients. The 6-month vascular properties of patients 60 years or older were also similar between L-arginine and placebo groups. Blum et al. [36] also reported that adding $9 \mathrm{~g}$ of L-arginine supplementation per day to standard anti-ischemic therapy had no effect on levels of NO, flowmediated brachial artery dilation or blood flow in 30 patients with stable coronary heart disease.

In a study to determine the effect of 2 weeks of L-arginine supplementation on the plasma L-arginine/ADMA ratio in men with stable angina, L-arginine supplementation increased the ratio by $60 \%$. However, despite the increase in the L-arginine/ADMA ratio there was no reduction in oxidative stress or improvement in endothelial function [37]. Similarly, L-arginine infusion did not augment acetylcholine-mediated forearm blood flow in hypertensive participants [38] or improve the vascular reactivity of patients with peripheral artery disease after 6 months of oral supplementation [39].

Jahangi et al. [40] carried out a comprehensive evaluation of endothelial function in coronary artery disease patients after L-arginine or L-arginine plus creatine supplementation. They found that 4 days of supplementation with either supplement had no effect on brachial artery diameter, blood flow, reactive hyperemia, flow-mediated dilation, or nitroglycerin-mediated dilation. Even after adjusting for covariates such as tobacco use or previous stroke, vascular function was not improved by supplementation. Finally, in a study in which a meta-analysis was used to evaluate the effect of L-arginine supplementation in individuals with cardiovascular disease, obesity, or diabetes, L-arginine was found not to improve post-ischemia hyperemia [41].

\section{Platelet and monocyte regulation}

As previously discussed, Blum et al. [36] found that 9g of arginine per day for 28 days produced no effect on flow mediated dilation of the brachial artery, but they also found that it had little effect on the cell adhesion molecules E-selectin, intercellular adhesion molecule- 1 or vascular cell adhesion molecule-1. Similar results were reported by Abdelhamed et al. [42] while studying the effects of L-arginine on patients with hypercholesterolemia. After oral supplementation of L-arginine for two weeks, there were no improvements noted in endothelial function, platelet aggregation or soluble levels of E-selectin or P-selectin. Wolf et al. [18] also evaluated platelet function in hypercholesterolemic subjects. The patients were randomized in a double-blind fashion to receive placebo or 8.4g per day of L-arginine. After 2 weeks of treatment with L-arginine, platelet reactivity was modestly reduced, but the reduction was not statistically significant.

\section{Hypertension}

Although a number of studies suggest that blood pressure can be lowered significantly with L-arginine supplementation, there are an equal number of studies that have failed to demonstrate this effect. For example, Neri et al. [43] enrolled 80 pregnant women with mild chronic hypertension and randomized them into two groups. One group received a placebo and the other group received an L-arginine supplement. After 10 to 12 weeks of treatment there was no difference in blood pressure between groups. Similar results 
were also found by Adams et al. [7], who investigated the effects of L-arginine in patients with premature coronary artery disease. Using a placebo-controlled, crossover experimental design, the patients $(\mathrm{N}=10 \mathrm{men})$ were provided $7 \mathrm{~g}$ of $\mathrm{L}$-arginine 3 times per day or placebo for 3 days, with a washout period of 10 days. No changes were seen in blood pressure, endothelium-independent dilatation of the brachial artery, heart rate or fasting plasma lipid levels.

The effect of L-arginine supplementation has also been studied on the blood pressure of patients with peripheral artery disease and hypercholesterolemia. Patients with peripheral artery disease were provided $24 \mathrm{~g}$ of L-arginine per day for 8 weeks with no improvement of either systolic or diastolic blood pressure [13]. Patients with hypercholesterolemia were provided $7 \mathrm{~g}$ of L-arginine three times per day for 4 weeks or placebo. Although endothelium dysfunction was improved, there were no differences in blood pressure noted within or across treatment groups [11]. In a rather unique study, West et al. [44] investigated the effects of L-arginine supplementation on the blood pressure of hypercholesterolemic patients while they were under stress conditions. They provided the patients $12 \mathrm{~g}$ of L-arginine per day for 3 weeks and found that diastolic blood pressure was significantly lowered when the subjects were under mental or physical stress, but systolic blood pressure was unaffected.

The effects of L-arginine supplementation on healthy normotensive men have also been investigated. Ast et al. [28] found that 4 weeks of supplementation with either $6 \mathrm{~g}$ or $12 \mathrm{~g}$ of L-arginine led to a non-significant decrease of systolic and diastolic blood pressure. Likewise, Adams et al. [17] reported that $7 \mathrm{~g}$ of L-arginine provided 3 times per day for 3 days did not lower the blood pressure of normotensive, young, healthy men or improve endothelial-dependent dilation.

\section{Cardiovascular disease and exercise capacity}

Peripheral vascular disease significantly limits physical activity and work capacity due to limited muscle blood flow secondary to reduce NO production. Therefore, Wilson et al. [39] investigated the effects of long-term L-arginine supplementation on NO production, vascular reactivity and functional capacity in this patient population. Patients were randomly assigned to receive either $3 \mathrm{~g}$ of L-arginine per day or placebo. Surprisingly, after 6 months of treatment, improvement in walking distance was found to be significantly better in the placebo group than the L-arginine group. Furthermore, flow-mediated dilation and systemic NO production were not improved by L-arginine supplementation.

In another study, the exercise capacity of men with obstructive coronary artery disease and stable angina were studied before and after 1 month of L-arginine supplementation (15g per day) or placebo. Symptom-limited standard Bruce protocol exercise tests were performed along with time to $1 \mathrm{~mm}$ ST depression, and time to onset of symptoms. Improvement in exercise time was noted in both the L-arginine-supplemented and placebo groups, but there was no difference found between groups. Likewise, there were no group differences for changes in rate pressure product, time to $1 \mathrm{~mm}$
ST depression or time to onset of symptoms [37]. These findings are supported by the study of Kanaya et al. [45], who reported that infusion of L-arginine in chronic heart disease patients had no effect on indices of exercise capacity including peak oxygen consumption, anaerobic threshold and exercise time. Similar results have also been noted in patients with hypercholesterolemia [46].

There is also little evidence that L-arginine supplementation will improve aerobic exercise endurance in healthy individuals $[47,48]$. For example, Sunderland et al. [48] supplemented 18 trained endurance cyclists with $6 \mathrm{~g}$ of L-arginine twice a day for 4 weeks. Post treatment results revealed L-arginine supplementation had no effect on maximal oxygen consumption or ventilator threshold.

\section{Adverse Effects of L-arginine Supplementation}

\section{Review of adverse events}

In addition to the evidence that L-arginine supplementation may be ineffective in treatment of cardiovascular disease and heart failure, there is also evidence that prolonged use of high dosages may have negative consequences. For example, Schulman et al. [35] investigated the long-term effects of L-arginine supplementation on coronary heart disease patients starting within a few days following their first myocardial infarction. Patients $(\mathrm{N}=153)$ were randomly assigned to receive $3 \mathrm{~g}$ of L-arginine three times per day or placebo. After 6 months of treatment there were 12 clinical events in the L-arginine group verses 7 in the placebo group. Clinical events included death, myocardial infarction and hospitalization for heart failure. More disturbing was the death of 6 patients in the L-arginine group compared with no deaths in the placebo group. The study was terminated after 6 months. The adverse effects of long-term L-arginine supplementation have also been noted in patients with peripheral vascular disease. Wilson et al. [39] reported that administering $3 \mathrm{~g}$ of L-arginine 3 times per day for 6 months resulted in functional capacity being attenuated in patients receiving L-arginine. Also, neither measures of vascular function nor systemic NO production were improved by L-arginine supplementation. It was observed that plasma ornithine levels were increased with L-arginine treatment, suggesting that intestinal arginase may have been induced and caused development of tolerance to L-arginine supplementation.

\section{Possible reasons for adverse events}

There are a number of possible reasons for $\mathrm{L}$-arginine supplementation to be ineffective or to cause adverse events. First, studies that have demonstrated improvements in cardiovascular function and blood pressure with L-arginine supplementation have required dosages of 6 to $24 \mathrm{~g}$ of L-arginine per day $[29,49]$. Such high levels of L-arginine over time could induce increased expression of arginase, which metabolizes L-arginine to urea and ornithine [50]. Therefore, an increased expression of arginase could reduce availability of L-arginine as substrate for eNOS and reduce NO production. It has also been found that over expression of arginase due to chronic supplementation of L-arginine can accelerate endothelial cell senescence, increase adhesion molecule 
expression, cause uncoupling of eNOS and lower NO production [51]. This of course can lead to a reduced vascular reactivity and propagation of atherosclerosis and coronary heart disease.

It should be noted that enhanced arginase activity has been implicated in a number of medical conditions such as endothelial dysfunction, atherosclerosis, hypertension, type 2 diabetes, and pulmonaryhypertension [52-56]. Second, high L-argininelevels have been found to inhibit dimethylarginine dimethylaminohydrolase, the enzyme responsible for ADMA metabolism to L-citrulline [57]. As previously discussed, ADMA is a competitive inhibitor of eNOS. Decreasing the L-arginine/ADMA ratio lowers eNOS activity and has been associated with vascular dysfunction, reduced renal function, hypertension and heart disease [58].

Third, supplementing with high concentrations of L-arginine creates a methylation demand, resulting in an increase in L-homocysteine accumulation [59]. Hyperhomocysteinemia is associated with increased risk of coronary artery disease, atherosclerosis, hypertension and stroke [60-63]. Furthermore, hyperhomocysteinemia is associated with elevated ADMA levels owing to the ability of homocysteine to inhibit dimethylarginine dimethylaminohydrolase [64].

Fourth, cardiovascular disease, hypercholesterolemia, type 2 diabetes and other metabolic disorders can result in the uncoupling of eNOS [5,6]. This uncoupling is primarily caused by a reduction in intracellular tetrahydrobiopterin availability secondary to oxidative stress, elevated levels of homocysteine, aging and inadequate nutrition $[65,66]$. Tetrahydrobiopterin is a necessary cofactor involved in the eNOS reaction. When unavailable, eNOS changes its functional profile from oxidizing L-arginine and generating NO to reducing molecular oxygen to superoxide anions $[51,61,65,67]$. Superoxide anions can scavenge NO to form peroxynitite and also lead to the production of other reactive oxygen species $[5,6]$. Aside from removing NO by superoxide anion scavenging, the free radicals generated can increase oxidative stress further damaging the endothelium and creating a vicious cycle [59]. Supplementing with high concentrations of L-arginine will only exacerbate this situation.

\section{Conclusion}

The infusion or oral supplementation of L-arginine has been found to improve vascular reactivity, blood pressure, platelet and monocyte function, and exercise capacity in patients with hypertension, heart failure, peripheral vascular disease, and other metabolic complications. However, the amount of L-arginine required to be efficacious is relatively high, between 6 to $24 \mathrm{~g}$ per day. Moreover, the durations of these studies have been limited, for the most part, to only 3 days to 6 weeks in length. Conversely, there are a number of studies that do not support the use of L-arginine supplementation for improvement in cardiovascular related diseases and indicate that under some conditions L-arginine supplementation could cause an adverse event. This is particularly true for studies of long duration.
There are several possible explanations for the ineffectiveness of prolonged, high dose supplementation of L-arginine. These include the development of tolerance to L-arginine due to over expression of arginase. Increasing the activity of arginase could rapidly metabolize L-arginine and lower its availability as substrate for eNOS. High dosages of L-arginine could also inhibit dimethylarginine dimethyaminohydrolase, the enzyme responsible for metabolizing ADMA. A reduction in ADMA metabolism could affectively decrease the L-arginine/ADMA ratio and result in eNOS inhibition. The supplementing of high concentrations of L-arginine can also increase methylation demand inadvertently raising the homocysteine level, which is associated with increased risk of developing atherosclerosis, hypertension, coronary heart disease and other cardiovascular complications.

Finally, cardiovascular disease and other metabolic disorders are associated with an uncoupling of eNOS, converting it from a NO generating enzyme to a free radical generating enzyme. Providing high concentrations of L-arginine to an uncoupled eNOS would therefore increase oxidative stress imparting more damage than repair in the vascular system. These findings bring into question the feasibility of using L-arginine supplementation long-term to treat cardiovascular disease and related conditions. Because of the possible contraindications associated with long-term use of L-arginine, it is also prudent to question its use in other nutritional supplements.

\section{References}

1. Wu G, Morris SM (1998) Arginine metabolism: nitric oxide and beyond. Biochem J 336(Pt 1): 1-17.

2. Förstermann U, Closs EI, Pollock JS, Nakane M, Schwarz P, et al. (1994) Nitric oxide synthase isozymes. Characterization, purification, molecular cloning, and functions. Hypertension 23(6 Pt 2): 1121-1131.

3. Förstermann U, Sessa WC (2017) Nitric oxide synthases: regulation and function. Eur Heart J 33(7): 829-837.

4. Taddei S, Virdis A, Ghiadoni L, Salvetti G, Bernini AM, et al. (2001) Agerelated reduction of NO availability and oxidative stress in humans. Hypertension 38(2): 274-279.

5. Förstermann U, Li H (2011) Therapeutic effect of enhancing endothelial nitric oxide synthase (eNOS) expression and preventing eNOS uncoupling. Br J Pharmacol 164(2): 213-223.

6. Gielis JF, Lin JY, Wingler K, Schil PEY, Schmidt HH, et al. (2011) Pathogenetic role of eNOS uncoupling in cardiopulmonary disorders. Free Radical Biology and Medicine 50(7): 765-776.

7. Adams MR, Credie R, Jessup W, Robinson J, Sullivan D, et al. (1997) Oral $\mathrm{L}$-arginine improves endothelium-dependent dilatation and reduces monocyte adhesion to endothelial cells in young men with coronary artery disease. Atherosclerosis 129(2): 261-269.

8. Böger SMB, Böger RH, Alfke H, Heinzel D, Tsikas D, et al. (1996) L-arginine induces nitric oxide-dependent vasodilation in patients with critical limb ischemia. A randomized, controlled study. Circulation 93(1): 85-90.

9. Böger RH, Böger SMB, Thiele W, Creutzing A, Alexander K, et al. (1998) Restoring vascular nitric oxide formation by L-arginine improves the symptoms of intermittent claudication in patients with peripheral arterial occlusive disease. Journal of the American College of Cardiology 32(5): 1336-1344. 
10. Palloshi A, Fragasso G, Piatti P, Monti LD, Setola E, et al. (2004) Effect of oral L-arginine on blood pressure and symptoms and endothelial function in patients with systemic hypertension, positive exercise tests, and normal coronary arteries. American Journal of Cardiology 93(7): 933-935.

11. Clarkson P, Adams MR, Powe AJ, Donald AE, McCredie R, et al. (1996) Oral L-arginine improves endothelium-dependent dilation in hypercholesterolemic young adults. J Clin Invest 97(8): 1989-1994.

12. Miller AL (2006) The effects of sustained-release-L-arginine formulation on blood pressure and vascular compliance in 29 healthy individuals. Altern Med Rev 11(1): 23-29.

13. Bode-Böger, S.M., Muke, J., Surdacki, A., Brabant, G., Böger, R.H. and Frölich, J.C. (2003) "Oral L-arginine improves endothelial function in healthy individuals older than 70 years", Vascular Medicine Vol. 8 pp. 77-81.

14. Lerman A, Burnett JC, Higano ST, McKinley LJ, Holmes DR (1998) Longterm L-arginine supplementation improves small-vessel coronary endothelial function in humans. Circulation 97(21): 2123-2128.

15. Ivy JL (2019) Inorganic nitrate supplementation for cardiovascular health. Methodist DeBakey Cardiovascular Journal 15(3): 200-206.

16. Machha A, Schechter AN (2011) Dietary nitrite and nitrate: a review of potential mechanisms of cardiovascular benefits. Eur J Nutr 50(5): 293303.

17. Adams MR, Forsyth CJ, Jessup W, Robinson J, Celermajer DS (1995) Oral L-arginine inhibits platelet aggregation but does not enhance endothelium-dependent dilation in healthy young men. Journal of the American College of Cardiology 26: 1054-1061.

18. Wolf A, Zalpour C, Theilmeier G, Wang BY, Ma A, et al. (1997) Dietary L-arginine supplementation normalizes platelet aggregation in hypercholesterolemic humans. Journal of the American College of Cardiology 29(3): 479-485.

19. Chan JR, Böger RH, Böger SM, Tangphao O, Tsao PS, et al. (2000) Asymmetric dimethylarginine increases mononuclear cell adhesiveness in hypercholesterolemic humans. Arterioscler Thromb Vasc Biol 20(4): 1040-1046.

20. Webb AJ, Patel N, Loukogeorgakis S, Okorie M, Aboud Z, et al. (2008) Acute blood pressure lowering, vasoprotective and anti-platelet properties of dietary nitrate via bioconversion to nitrite. Hypertension 51(3): 784-790.

21. Vanhatalo A, Bailey SJ, Blackwell JR, DiMenna FJ, Pavey TG, et al. (2010) Acute and chronic effects of dietary nitrate supplementation on blood pressure and the physiological responses to moderate-intensity and incremental exercise. Am J Physiol Regul Integr Comp Physiol 299(4): R1121-R1131.

22. Kenjale AA, Ham KL, Stabler T, Robbins JL, Johnson JL, et al. (2011) Dietary nitrate supplementation enhances exercise performance in peripheral arterial disease. J Appl Physiol 110(6): 1582-1591.

23. Lansley KE, Winyard PG, Fulford J, Vanhatalo A, Bailey SJ, et al. (2011) Dietary nitrate supplementation reduces the $\mathrm{O}_{2}$ cost of walking and running: a placebo-controlled study. J Appl Physiol 110(3): 591-600.

24. Facchinetti F, Saade GR, Neri I, Pizzi C, Longo M, et al. (2007) L-arginine supplementation in patients with gestational hypertension: a pilot study. Hypertension Pregnancy 26(1): 121-130.

25. Battaglia C, Mancini F, Battaglia B, Facchinetti F, Artini PG, et al. (2010) L-arginine plus drospirenone-ethinyl estradiol in the treatment of patients with PCOS: a prospective, placebo controlled, randomized pilot study. Gynecological Endocrinology 26(12): 861-868.

26. Piatti PM, Monti LD, Valsecchi G, Magni F, Setola E, et al. (2001) Longterm oral L-arginine administration improves peripheral and hepatic insulin sensitivity in type 2 diabetic patients. Diabetes Care 24(5): 875880.
27. Lucotti P, Setola E, Monti LD, Galluccio E, Costa S, et al. (2006) Beneficial effects of a long-term oral L-arginine treatment added to a hypocaloric diet and exercise training program in obese, insulin-resistant type 2 diabetic patients. Am J Physiol Endocrinol Metab 291(5): E906-E912.

28. Ast J, Jablecka A, Bogdanski P, Smolarek I, Krauss H, et al. (2010) Evaluation of the antihypertensive effect of L-arginine supplementation in patients with mild hypertension assessed with ambulatory blood pressure monitoring. Med Sci Monit 16(5): CR266-CR271.

29. Dong JY, Qin LQ Zhang Z, Zhao Y, Wang J, et al. (2011) Effect of oral L-arginine supplementation on blood pressure: A meta-analysis of randomized, double-blind, placebo-controlled trials. Am Heart J 162(6): 959-965.

30. Ceremuzynski L, Chamiec T, Cedro KH (1997) Effect of supplemental oral L-arginine on exercise capacity in patients with stable angina pectoris. American Journal of Cardiology 80(3): 331-333.

31. Doutreleau S, Mettauer B, Piquard F, Rouyer O, Schaefer A, et al. (2006) Chronic L-arginine supplementation enhances endurance exercise tolerance in heart failure patients. Int J Sports Med 27(7): 567-572.

32. Hambrecht R, Hilbrich L, Erbs S, Gielen S, Fiehn E, et al. (2000) Correction of endothelial dysfunction in chronic heart failure: additional effects of exercise training and oral L-arginine supplementation. J Am Coll Cardiol 35(3): 706-713.

33. Maxwell AJ, Cooke JP (1998) Cardiovascular effects of L-arginine. Current Opinion in Nephrology and Hypertension 7: 63-70.

34. Rector TS, Bank AJ, Mullen KA, Tschumperlin LK, Sih R, et al. (1996) Randomized, double-blind, placebo-controlled study of supplemental oral L-arginine in patients with heart failure. Circulation 93(12): 21352141.

35. Schulman SP, Becker LC, Kass DA, Champion HC, Terrin ML, et al. (2006) L-arginine therapy in acute myocardial infarction. The vascular interaction with age in myocardial infarction (VINTAGE MI) randomized clinical trial. JAMA 295(1): 58-64.

36. Blum A, Hathaway L, Mincemoyer R, Schenke WH, Kirby M, et al. (2000) Oral L-arginine in patients with coronary disease on medical management. Circulation 101(18): 2160-2164.

37. Walker HA, McGing E, Fisher I, Böger RH, Böger SMB, et al. (2001) Endothelium-dependent vasodilation is independent of the plasma L-Arginine/ADMA ratio in men with stable angina. Lack of effect of oral l-arginine on endothelial function, oxidative stress and exercise performance. Journal of the American College of Cardiology 38(2): 499505 .

38. Panza JA, Casino PR, Badar DM, Quyyum AA (1993) Effect of increased availability of endothelium-derived nitric oxide precursor on endothelium-dependent vascular relaxation in normal subjects and in patients with essential hypertension. Circulation 87(5): 1475-1481.

39. Wilson AM, Harada R, Nair N, Balasubramanian N, Cooke JP (2007) $\mathrm{L}$-arginine supplementation in peripheral arterial disease. Circulation 116(2): 188-195

40. Jahangir E, Handy D, Palmisano J, Loscalzo J (2009) The effect of L-arginine and creatine on vascular function and homocysteine metabolism. Vascu Med 14(3): 239-248.

41. Krause JR, Krause M, Roch IMG, Umpierre D, Fayh APT (2019) Association of L-arginine supplementation with markers of endothelial function in patients with cardiovascular or metabolic disorders: A systematic review of meta-analysis. Nutrients 11(1): 15.

42. Abdelhamed IA, Reis SE, Sane DC, Brosnihan KB, Robert B, et al. (2003) No effect of an L-arginine-enriched medical food (Heart Bars) on endothelial function and platelet aggregation in subjects with hypercholesterolemia. American Heart Journal 145(3): e15.

43. Neri I, Monari F, Sgarbi L, Berardi A, Masellis G, et al. (2010) L-arginine supplementation in women with chronic hypertension: impact on blood 
pressure and maternal and neonatal complications. J Matern Fetal Neonatal Med 23(12): 1456-1460.

44. West SG, Krick AL, Brown P, Mariotti F (2005) Oral L-arginine improves hemodynamic responses to stress and reduces plasma homocysteine in hypercholesterolemic men. Journal of Nutrition 135(2): 212-217.

45. Kanaya Y, Nakamura M, Kobayashi N, Hiramori K (1999) Effects of L-arginine on lower limb vasodilator reserve and exercise capacity in patients with chronic heart failure. Heart 81(5): 512-517.

46. Wennmalm A, Edlund A, Granstrom EF, Wiklund O (1995) Acute supplementation with the nitric oxide precursor L-arginine does not improve cardiovascular performance in patients with hypercholesterolemia. Atherosclerosis 118(2): 223-231.

47. Liu TH, Wu CL, Chiang CW, Lo YW, Tseng HF, et al. (2009) No effect of short-term arginine supplementation on nitric oxide production, metabolism and performance in intermittent exercise in athletes. J Nutr Biochem 20(6): 462-468.

48. Sunderland KL, Greer F, Morales J (2001) V02max and ventilatory threshold of trained cyclists are not affected by 28-day L-arginine supplementation. J Strength Cond Res 25(3): 833-837.

49. Preli RB, Klein KP, Herrington DM (2002) Vascular effects of dietary L-arginine supplementation. Atherosclerosis 162(1): 1-15.

50. Scalera F, Closs EI, Flick E, Lobenhoffer J, Boissel JP, et al. (2009) Paradoxical effect of L-arginine: acceleration of endothelial cell senescence. Biochemical and Biophysical Research Communications 386(4): 650-655.

51. Xiong Y, Fru MF, Yu Y, Montani JP, Ming XF, et al. (2014) Long term exposure to L-arginine accelerates endothelial cell senescence through arginase-II and S6K1 signaling. Aging (Albany NY) 6(5): 369-379.

52. Bivalacqua TJ, Hellstrom WJ, Kadowitz PJ, Champion HC (2001) Increased expression of arginase II in human diabetic corpus cavernosum: in diabetic-associated erectile dysfunction. Biochemical and Biophysical Research Communications 283(4): 923-927.

53. Hein TW, Zhang C, Wang W, Chang CI, Thengchaisri N, et al. (2003) Ischemia-reperfusion selectively impairs nitric oxide-mediated dilation in coronary arterioles: counteracting role of arginase. FASEB Journal 17(15): 2328-2330.

54. Morris CR, Morris SM, Hagar W, Warmerdam J, Claster S, et al. (2003) Arginine therapy: a new treatment for pulmonary hypertension in sickle cell disease? American Journal of Respiratory and Critical Care Medicine 168(1): 63-69.

55. Zhang C, Hein TW, Wang W, Miller MW, Fossum TW, et al. (2004) Upregulation of vascular arginase in hypertension decreases nitric oxide-mediated dilation of coronary arterioles. Hypertension 44(6): 935-943.

56. Morris CR, Kato GJ, Poljakovic M, Wang X, Blackwelder WC, et al. (2005) Dysregulated arginine metabolism, hemolysis-associated pulmonary hypertension, and mortality in sickle cell disease. JAMA 294(1): 81-90.

57. Wang J, Sim AS, Wang XL, Wilcken DE (2006) L-Arginine regulates asymmetric dimethylarginine metabolism by inhibiting dimethylarginine dimethylaminohydrolase activity in hepatic (HepG2) cells. Cell Mol Life Sci 63(23): 2838-2846.

58. Wilcken DEL, Sim AS, Wang J, Wang XL (2007) Asymmetric dimethylarginine (ADMA) in vascular, renal and hepatic disease and the regulatory role of L-arginine on its metabolism. Molecular Genetics and Metabolism 91(4): 309-317.

59. Loscalzo J (2000) What we know and don't know about L-arginine and NO. Circulation 101(18): 2126-2129.

60. Ganguly P, Alam SF (2015) Role of homocysteine in the development of cardiovascular disease. Nutr J 14: 6.

61. Loscalzo J (2003) Adverse effects of supplemental L-arginine in atherosclerosis. Arteriosclerosis, Thrombosis, and Vascular Biology 23: 3-5.

62. McCully KS (2016) Homocysteine, infections, polyamines, oxidative metabolism, and the pathogenesis of dementia and atherosclerosis. Journal of Alzheimers Disease 54(4): 1283-1290.

63. Schaffer A, Verdoia M, Cassetti E, Marino P, Suryapranata H, et al. (2014) Relationship between homocysteine and coronary artery disease. Results from a large perspective cohort study. Thromb Res 134(2): 288293.

64. Stuhlinger MC, Tsao PS, Her JH, Kimoto M, Balint RF, et al. (2001) Homocysteine impairs the nitric oxide synthase pathway: role of asymmetric dimethylarginine. Circulation 104(21): 2569-2575.

65. Topal G, Brunet A, Millanvoye E, Boucher JL, Rendu F, et al. (2004) Homocysteine induces oxidative stress by uncoupling of NO synthase activity through reduction of tetrahydrobiopterin. Free Radic Biol Med 36(12): 1532-1541.

66. Yang YM, Huang A, Kaley G, Sun D (2009) eNOS uncoupling and endothelial dysfunction in aged vessels. American Journal of PhysiologyHeart and Circulatory Physiology 297(5): H1829-H1836.

67. Landmesser U, Dikalov S, Price SR, Cann L, Fukai T, et al. (2003) Oxidation of tetrahydrobiopterin leads to uncoupling of endothelial cell nitric oxide synthase in hypertension. J Clin Invest 111(8): 1201-1209. 